\section{Commentary: The role of del Nido cardioplegia in adult cardiac surgery: The jury is still out}

\author{
Harold L. Lazar, MD
}

del Nido cardioplegia solution (DNS), administered as a single dose during aortic clamping, was initially developed for pediatric cardiac surgery to improve "surgical work flow" by limiting the need for multiple reinfusions. ${ }^{1}$ It has since been adopted by cardiac surgeons to reduce crossclamp (XC) and cardiopulmonary bypass (CBP) times in an attempt to decrease perioperative morbidity and mortality. Retrospective studies involving coronary artery bypass graft procedures and isolated aortic valve replacements have demonstrated that DNS does significantly decrease $\mathrm{XC}$ and $\mathrm{CPB}$ times, but this has not resulted in any significant improvement in morbidity or mortality compared with traditional multidose blood cardioplegia techniques. $^{2-5}$ Most of the studies have been retrospective and small in size, consisting of a cohort of stable, elective patients with minimal comorbidities, preserved left ventricular function without right ventricular dysfunction, undergoing noncomplex operative procedures, and with $\mathrm{XC}$ times $<60$ minutes. In fact, a prospective, randomized study in low risk patients undergoing coronary artery bypass graft procedures comparing DNC to multidose blood cardioplegia found no difference in postoperative morbidity or mortality. ${ }^{6}$ Furthermore, in that study, one-third of the DNS group patients actually received multiple doses of DNS. ${ }^{6}$

Lenoir and colleagues ${ }^{7}$ sought to enhance our knowledge of DNS use in adult cardiac surgery by reporting their results in patients undergoing complex procedures requiring prolonged periods of cardioplegic arrest. In 283 patients undergoing aortic root repairs using either a Ross or valvesparing procedure, 110 patients were $1: 1$ propensity matched between DNS and multidose blood cardioplegia. The patient cohort consisted of young (average age, 48 years), elective

\footnotetext{
From the Division of Cardiac Surgery, the Boston University School of Medicine, Boston, Mass.

Disclosures: Author has nothing to disclose with regard to commercial support.

Received for publication Jan 20, 2020; accepted for publication Jan 21, 2020; available ahead of print Feb 7, 2020.

Address for reprints: Harold L. Lazar, MD, Division of Cardiac Surgery, Boston University School of Medicine, 80 E Concord St, Boston, MA 02118 (E-mail: harold.1. lazar@gmail.com).

J Thorac Cardiovasc Surg 2021;162:523-5

$0022-5223 / \$ 36.00$

Copyright (c) 2020 by The American Association for Thoracic Surgery

https://doi.org/10.1016/j.jtcvs.2020.01.062
}

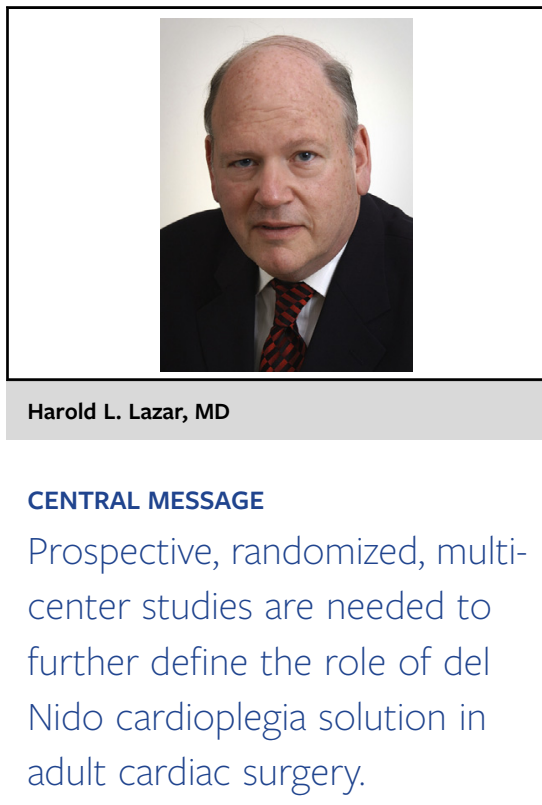

patients; predominately in New York Heart Association functional class I or II $(88 \%$ ), with minimal comorbidities (eg, $13 \%$ had diabetes) and average preserved left ventricular ejection fraction $(59 \%)$. Few patients required additional concomitant procedures (eg, $5 \%$ underwent a coronary artery bypass graft procedure and $2 \%$ underwent a mitral procedure). The mean European System for Cardiac Operative Risk Evaluation II score was 1.56. DNS consisted of a single antegrade dose of $1250 \mathrm{~mL}$ at $4^{\circ} \mathrm{C}$. After 60 minutes of XC, an additional $625 \mathrm{~mL}$ DNS was administered if the $\mathrm{XC}$ time was estimated to exceed an additional 90 minutes. In patients receiving multidose blood cardioplegia, an initial antegrade dose of $1000 \mathrm{~mL}$ was followed by $400 \mathrm{~mL}$ every 15 to $20 \mathrm{mi}-$ nutes. Topical cooling was not used and systemic hypothermia was used only for arch procedures. The majority of patients in both groups (54\%), received an antegrade/retrograde delivery technique.

Patients protected with DNS had significantly decreased $\mathrm{CPB}(163 \pm 5 \mathrm{~min}$ vs $181 \pm 5 \mathrm{~min} ; P=.01)$ and $\mathrm{XC}$ times $(145 \pm 5 \mathrm{~min}$ vs $161 \pm 4 \mathrm{~min} ; P=.006)$ compared with multidose blood cardioplegia patients. In both the matched and unmatched patients, there was no difference in postoperative morbidity or mortality, or the need for blood products or the use of intravenous insulin between the DNS and multidose blood cardioplegia patients. Although the incidence of myocardial infarction was twice as great in the DNS group compared with the multidose blood cardioplegia group ( $18 \%$ vs $9 \%$ ), this was not statistically significant $(P=.16)$. However, in patients with $\mathrm{XC}$ time $>180$ minutes, postoperative creatine kinase-MB levels were significantly higher in the DNS group compared 
with the multidose blood cardioplegia group $(75.1 \mu \mathrm{g} / \mathrm{L}$ vs $60.5 \mu \mathrm{g} / \mathrm{L} ; P=.047)$ although there was no difference in postoperative morbidity or mortality. The immediate postoperative left ventricular ejection fraction was also similar between the groups.

As was the case in previous studies in patients protected with DNS, this study was retrospective and not randomized. The sample size was small due to propensity matching, which limited the statistical power. Not all patients were available to assess left ventricular ejection fraction at 1 year after the operation, so the long-term effects of the increase in cardiac enzymes is not known in all of the patients. The observed increase in creatine kinaseMB levels in this study was also noted by Yammine and colleagues $^{5}$ in a retrospective, propensity-matched patient series undergoing adult cardiac surgery using DNS. Similar to the results reported by Lenoir and colleagues, ${ }^{7}$ Yammine and colleagues ${ }^{5}$ found that the elevated enzyme levels resulted in no difference in morbidity or mortality immediately following surgery and for 1 year postoperatively.

DNS appears to be safe for low risk, elective patients with minimal comorbidities undergoing isolated coronary artery bypass grafting and aortic valve replacement procedures where the XC time is anticipated to be no longer than 60 minutes. With the new guidelines recommending transcatheter aortic valve replacement for low-risk patients, many patients in need of aortic valve replacement will now undergo a percutaneous procedure. Patients undergoing surgical aortic valve replacement will have more complex anatomy that might require concomitant procedures and require longer $\mathrm{XC}$ times and the most optimal forms of myocardial protection. There are currently no data to suggest that DNS will provide adequate protection for those patients with right ventricular dysfunction and those with reduced ejection fraction who require longer $\mathrm{XC}$ times for more complex procedures. Patients with multivessel coronary disease and those with left ventricular hypertrophy in which the distribution of cardioplegia is not uniform may also not be good candidates for DNS. Rao and colleagues ${ }^{8}$ found that when thermographic imaging was used to assess cardioplegic distribution, patients undergoing coronary artery bypass grafting with multivessel disease protected with DNS required an average of 6 doses of cardioplegia to prevent increases in global myocardial temperature of $10^{\circ} \mathrm{C}$ or higher. During a mean XC time of 132 minutes, this required an average volume of $2710 \mathrm{~mL}$ DNS. Another area of concern with DNS is when and how much additional cardioplegia should be given if the XC time exceeds 60 minutes. Infusing multiple doses of DNS may be detrimental due to increased concentrations of lidocaine in the myocardium. A close relationship exists between lidocaine dose and toxicity, which can result in peripheral vasodilatation, negative inotropy, ventricular arrhythmias, and central nervous system side effects such as seizures. ${ }^{9}$

Based on the results from their study, Lenoir and colleagues ${ }^{7}$ conclude that caution is warranted in adopting DNS in aortic surgery requiring long ischemic times and that further studies are required to establish the exact role of DNS in complex cardiac surgeries. They also propose that if patients require longer than expected ischemic times, surgeons should switch from DNS to multidose blood cardioplegia after 90 minutes of aortic XC rather than attempting to redose with DNS to avoid the potential for lidocaine toxicity. I wholeheartedly agree with these conclusions. Multidose blood cardioplegia has been the gold standard for achieving optimal myocardial protection in all types of adult cardiac surgery procedures. Before we adopt and endorse DNS, which may save 10 to 15 minutes of XC time-which has not translated into improved postoperative outcomesmore data are needed. Where will these data come from? Previously, I called for a multicenter Cardiothoracic Surgery Network-sponsored trial that would be prospectively randomized and adequately powered, including all types of adult cardiac surgery procedures (ie, both urgent and emergent cases) with established protocols for both DNS and multidose blood cardioplegia. ${ }^{10}$ Important end points should include not only XC and CBP times and operative mortality, but also need for inotropic support, number of blood transfusions, the incidence of perioperative myocardial infarction, changes in ejection fraction, and intensive care unit and hospital length of stay. It is important to remember that it is the quality of myocardial protection, and not necessarily the time during which myocardial protection is provided that will determine perioperative outcomes. The high quality data obtained from prospective, multicenter trials will help to determine whether DNS is effective in protecting all types of patients undergoing all types of adult cardiac surgery under all conditions. Until then, the jury is still out regarding the role of DNS in adult cardiac surgery.

\section{References}

1. Matte GS, del Nido PJ. History and use of del Nido cardioplegia solution at Boston's Children's Hospital. J Extracorporeal Technol. 2012;44:98-103.

2. Timek T, Willekes C, Hulme O, Himelhoch B, Nadeau D, Borgman A, et al. Propensity matched analysis of del Nido cardioplegia in adult coronary artery bypass grafts. Ann Thorac Surg. 2016;101:2237-41

3. Mick SL, Robich MP, Houghtaling PL, Gillinov AM, Solesz EG, Johnston DR, et al. del Nido versus Buckberg cardioplegia in adult isolated valve surgery. J Thorac Cardiovasc Surg. 2015;149:626-36.

4. Sorbella RA, Akashi H, Yerebaken H, Najjar M, Mannan A, Williams MR, et al. Myocardial protection using del Nido cardioplegia solution in adult reoperative aortic valve surgery. J Card Surg. 2014;29:445-9.

5. Yammine M, Neely RC, Loberman D, Rajab TK, Grewal A, McGurk S, et al. The use of lidocaine containing cardioplegia in surgery for adult acquired heart disease. J Card Surg. 2015;30:677-84.

6. Ad N, Holmes SD, Massimiano PS, Rongione AJ, Fornaresio LM, Fitzgerald D. The use of del Nido cardioplegia in adult cardiac surgery: a prospective randomized trial. J Thorac Cardiovasc Surg. 2018;155:1011-8.

7. Lenoir M, Bouhout I, Jelassi A, Cartier R, Poirier N, El-HamamsyI, et al. del Nido cardioplegia versus blood cardioplegia in adult root surgery. J Thorac Cardiovasc Surg. 2021;162:514-22.e2. 
8. Rao P, Keenan JB, Rajab TK, Ferng A, Kim S, Khalpey Z. Intraoperative thermographic imaging to assess myocardial distribution of del Nido cardioplegia. $J$ Card Surg. 2017;32:812-5.
9. Brown DL, Skiendzielewski JJ. Lidocaine toxicity. Ann Emerg Med. 1980;9:627-9. 10. Lazar HL. del Nido cardioplegia-passing fad or here to stay? J Thorac Cardiovasc Surg. 2018;155:1009-10.
See Article page 514

\section{Commentary: Del Nido cardioplegic solution: Is it really better than any other?}

\author{
Frank W. Sellke, MD
}

The del Nido cardioplegic solution (DNS) has recently received a large amount of attention as a method to improve myocardial protection for both pediatric and adult patients undergoing cardiac surgery. Although some have proposed that the myocardial protection afforded by DNS is actually superior to other commonly used solutions, the real benefit of DNS is as a way to speed up an operation by limiting the times a surgeon needs to deliver the cardioplegia. DNS was originally developed for pediatric cardiac surgery as a single-dose formula. ${ }^{1}$ Although DNS has been studied in pediatric patients, its effectiveness in adults is still under investigation. DNS contains a base solution of Plasma-Lyte A (Baxter Healthcare Corp, Deerfield, Ill), which has an electrolyte composition similar to extracellular fluid. In the original formulation, the concentrations of electrolytes before the addition of cardioplegic additives are $140 \mathrm{mEq} / \mathrm{L}$ sodium, 5 $\mathrm{mEq} / \mathrm{L}$ potassium, $3 \mathrm{mEq} / \mathrm{L}$ magnesium, $98 \mathrm{mEq} / \mathrm{L}$ chloride, $27 \mathrm{mEq} / \mathrm{L}$ acetate, and $23 \mathrm{mEq} / \mathrm{L}$ gluconate, but this has been modified by many clinicians, including the authors of the study under consideration. The formulation of both original and modified versions serves as the crystalloid component, which is mixed with blood at a ratio of 4 parts crystalloid to 1 part fully oxygenated patient whole blood. Of note, it is a potassium-rich, lidocaine-containing solution with a

\footnotetext{
From the Alpert Medical School of Brown University, Providence, RI.

Supported by National Heart, Lung, and Blood Institute grants (Nos. HLRO1 46716 and RO1 128831).

Disclosures: Author has nothing to disclose with regard to commercial support.

Received for publication Jan 21, 2020; accepted for publication Jan 22, 2020; available ahead of print Feb 7, 2020.

Address for reprints: Frank W. Sellke, MD, Alpert Medical School of Brown University, Rhode Island Hospital, MOC 360, 2 Dudley St, Providence, RI 02903 (E-mail: frank_sellke@brown.edu).

J Thorac Cardiovasc Surg 2021;162:525-6

$0022-5223 / \$ 36.00$

Copyright (c) 2020 by The American Association for Thoracic Surgery

https://doi.org/10.1016/j.jtcvs.2020.01.061
}

Check for updates

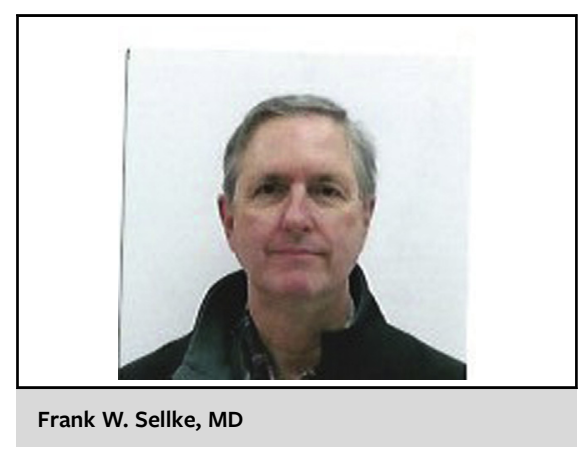

CENTRAL MESSAGE

Del Nido cardioplegic solution

may improve myocardial pro-

tection and increase the speed

of an operation. However,

caution must be taken to main-

tain optimal protection during

long operations.

lower hematocrit level than conventional blood-based cardioplegia and the only glucose and calcium in the delivered solution is from the patient blood mixed with the crystalloid component. The magnesium is a useful component to limit calcium influx and sequestration into cells.

Lenoir and colleagues ${ }^{2}$ examine the effectiveness of DNS compared with traditional blood cardioplegia on myocardial protection and clinical outcomes in patients undergoing prolonged aortic root surgery. Both solutions were initially delivered at $4^{\circ} \mathrm{C}$ but with different volumes. In the DNS group, after 60 minutes, an additional volume was administered if the myocardial ischemic time was anticipated to exceed 90 minutes. In the blood cardioplegia group, the solution was readministered every 15 to 20 minutes. Myocardial protection was assessed by gathering the highest postoperative creatine kinase-MB isotype levels and troponin $\mathrm{T}$ levels at 1, 12, 24, and 48 hours after surgery. Both groups did well, but there was a trend toward higher troponin $\mathrm{T}$ levels in the DNS group compared with standard blood cardioplegia 